\title{
A REPRESENTAÇÃO DOS INDÍGENAS NUM COTIDIANO ESCOLAR
}

\author{
DANILO CÉSAR SOUZA PINTO ${ }^{1}$ \\ UESB, BRASIL
}

DIANA BARRETO XAVIER ${ }^{2}$

PEDAGOGA LICENCIADA PELA UESB, BRASIL

\begin{abstract}
RESUMO: O artigo aborda a maneira como os indígenas são representados no Dia do Índio em uma escola pública de ensino fundamental no interior da Bahia. A pesquisa deve ser lida como um desdobramento da Lei 11.645/08 e a obrigatoriedade do tratamento da questão indígena em todas as escolas brasileiras. Por meio de entrevistas e observação participante, percebeu-se que nessas atividades, os indigenas são retratados sem que se leve em conta a sua diversidade e história, o que reflete numa representação que apaga suas culturas, produzindo estereótipos. Tal fato resulta na dificuldade de se compreender a relação dos indígenas com a sociedade brasileira na contemporaneidade. Ao acompanhar o planejamento e a realização dessa atividade comemorativa, os pesquisadores descreveram e refletiram sobre a forma como a instituição escolar contribui à formação de um estereótipo pretérito e folclórico sobre os índios, ao agenciar noções essencializadas a respeito das culturas e das histórias indígenas.
\end{abstract}

PALAVRAS-CHAVE: Educação. Lei 11.645/08. História do Brasil. O Ensino sobre as culturas indígenas na escola.

ABSTRACT: The article discusses how indigenous people are represented on the Indian Day in a public elementary school in a small town of Bahia. The research must be read like a consequence about Law 11.645/08 and compulsory treatment of the indigenous question in all Brazilian schools. Using interviews and participant observation in this activities, it was noticed that the indigenous people are represented without taking into account their diversity and history. Thus, they lose their culture and some stereotypes are produced about them. This fact causes difficulties to understand the relation of the indigenous people with the brazilian society in the contemporaneity. The researchers made a participant observation of the planning and the accomplishment of this commemorative activity. They described and reflected on how the institution contributes to the formation of a stereotype of the Indians by assembling essentialized notions about culture and history.

KEYWORDS: Education. Law 11.645/08. History of Brazil. Teaching about indigenous cultures at school.

\footnotetext{
${ }^{1}$ Professor do Departamento de Antropologia Social e do Programa de Pós-graduação em em Relações Étnicas e Contemporaneidade (Universidade Estadual do Sudoeste da Bahia, campus de Jequié, Brasil). Email: danilosouzap@uesb.edu.br

2 Licenciada em Pedagogia pela Universidade Estadual do Sudoeste da Bahia. E-mail: dianabxavier@yahoo.com.br
} 


\section{Introdução}

Às vésperas do dia 19 de abril, as escolas brasileiras movimentamse para comemorar o Dia do Índio. Nessa ocasião, os pais que têm filhos matriculados na educação infantil os recebem com rostos pintados, cocares de papel e pena na cabeça. Por meio desse tipo de expediente, a ideia é homenagear, lembrar e celebrar essa população que compõe e forma o Estado-nação brasileiro.

Este artigo tem por objetivo descrever e refletir sobre essa prática habitual nos espaços escolares em relação à data comemorativa, com base em pesquisa de campo realizada numa escola de ensino fundamental do município de Jequié (BA). Por respeito às questões éticas e também devido ao propósito do texto não ser uma investigação de fiscalização sobre as atividades do estabelecimento de ensino, mas de compreensão de uma prática, levando em conta a contextualização histórica e o modus operandi da abordagem à questão indígena no Brasil, o espaço escolar e os participantes não serão identificados ${ }^{3}$. Ainda que a reflexão seja contextual, pressupõe-se que possa remeter a situações que pululam por todo o país nessa data. ${ }^{4}$

A Lei $n^{0} 11645 / 08^{5}$ torna o estudo da história das culturas afrobrasileira e indígena obrigatório nas escolas. Trata-se de modificação da Lei $\mathrm{n}^{\circ} 10.639 / 2003$ e das Leis de Diretrizes de Bases ${ }^{6}$, as quais incluem a temática indígena. Isso representa uma conquista do movimento indígena no sentido de modificar e de aprimorar o entendimento promovido pelo espaço escolar sobre as sociedades indígenas do Brasil (BERGAMASCHI; GOMES, 2012). Cabe, com base na lei citada, investigar a forma como esta iniciativa tem sido aplicada nas escolas e se sua promulgação alterou as maneiras tradicionais de abordagem da questão indígena. Com isto, os autores não querem se colocar numa posição iluminista de universidade frente à educação básica. A ideia é justamente observar os problemas da escola sem perder de vista que se a escola reproduz uma imagem

\footnotetext{
${ }^{3}$ A pesquisa foi realizada com autorização da escola e dos professores envolvidos, que assinaram um Termo de Consentimento Livre e Esclarecido.

${ }^{4}$ Essa afirmação se baseia na experiência pessoal e profissional dos autores e é ratificada pela bibliografia sobre o tema. Bessa Freire (2000) mostra como a escola pensa a temática indígena sempre num congelamento folclórico do passado e circunscrito à disciplina História. Zamboni e Bergamaschi (2009, p. 67) demonstram como há a predominância nos livros didáticos de um índio genérico, sem diversidade, exótico, bárbaro ou romântico (bom selvagem), fadado a um fim inexorável, que só aparece no dia do índio ou na pré-história. Bergamaschi e Gomes (2012) pesquisando as atividades produzidas pelos discentes em duas escolas públicas de Ensino Fundamental no Rio Grande do Sul, uma com presença indígena e outra sem, vão descrever as imagens dos índios congelados num passado idílico, sem remetê-las à contemporaneidade, justamente na escola que não apresentava estudantes indígenas.

${ }^{5}$ Lei $^{\circ} 11.645 / 08,10$ de março de 2008: altera a Lei ${ }^{\circ}$ 9.394, de 20 de dezembro de 1996, modificada pela Lei $\mathrm{n}^{\circ} 10.639$, de 9 de janeiro de 2003, e estabelece as diretrizes e bases da educação nacional para incluir no currículo oficial da rede de ensino a obrigatoriedade da temática: História e Cultura Afro-Brasileira e Indígena.

${ }^{6}$ A Lei de Diretrizes e Bases da Educação Brasileira (LDB 9394/96) é responsável pelo sistema educacional brasileiro, da educação básica ao ensino superior, tanto da rede pública quanto da privada. A Lei $\mathrm{n}^{\circ}$ $11645 / 08$ foi incorporada à LDB, colocando diretrizes para seus cumprimentos em todos os níveis de ensino.
} 
estereotipada é também devido à universidade não problematizar e refletir adequadamente sobre essa realidade.

Em um texto introdutório de 1967, Cardoso de Oliveira (1971), talvez o principal autor a abordar a relação entre as sociedades indígenas e a nacional, marca a polaridade na forma como uma generalização estereotípica "índio" vem sendo formulada desde o início do processo de Conquista". De um lado, há uma concepção citadina do índio ingênuo, amante, protetor da natureza; de outro, dos habitantes das regiões circunvizinhas às populações indígenas, o traiçoeiro, o indomável e o preguiçoso - desdobramento da relação contextual que se tem com as frentes de expansão nacional e da relação de colonialismo interno (BOMFIL BATALLA, 1997; CASANOVA, 2006).

Essa dupla imagem pode ser, em retrospecto, encontrada nos registros dos séculos $\mathrm{XVI}$ e XVII, com a metáfora de um paraíso terreno, um éden puro e inocente perdido na América, visão inaugurada por Caminha em sua famosa Carta de achamento do Brasil (BETTERNCOURT, 1998) versus os selvagens, os comedores de gente ou, na sua extensão limite, os antropofágicos ou os canibais, a depender do contexto na relação, ou seja, se são índios amigos ou inimigos. Assim, em uma perspectiva, temos a figura dos que matam a fome com carne humana, que são repugnantes, e de outra perspectiva, aqueles que agem dessa forma por vingança na busca por prestígio ou novos nomes (CUNHA, 2012). Já nos séculos XVIII e XIX, a clivagem se constrói entre índios amigos e gentios bravos, de acordo com a posição em relação ao domínio colonial (CUNHA, 1998; MOÍSES, 1998), ou entre os primitivos sob a ótica evolucionista e os nobres selvagens do indianismo romântico ${ }^{8}$.

No século XVI, os índios eram ou bons selvagens para uso na filosofia moral europeia, ou abomináveis antropófagos para uso na colônia. No século XIX, eram, quando extintos, os símbolos nobres do Brasil independente e, quando de carne e osso, os ferozes obstáculos à penetração que convinha precisamente extinguir. Hoje, eles são seja os puros paladinos da natureza seja os inimigos internos, instrumentos da cobiça internacional sobre a Amazônia. (CUNHA, 2012, p. 122).

Tal duplicidade representacional coloca obstáculo na apreensão sobre a situação dos povos indígenas na contemporaneidade, especialmente nas versões escolares. Ao construir estereótipos sobre essa população de mais de 869 mil pessoas, não se vislumbra uma diversidade interna: 305 etnias e aproximadamente 274 línguas, segundo

\footnotetext{
${ }^{7}$ Forma mais adequada aos fatos históricos, outrora conhecidos como "descobrimento". Muitas escolas pelo Brasil ainda denominam o processo por esse termo, o que marca um ponto de vista anti-índigena, ao pressupor que se descobre um lugar sem a devida atenção ao fato de já estar ocupado.

${ }^{8}$ Dá-se o nome de indianismo romântico a um conjunto de obras literárias produzidas no século XIX, período da formação de uma ideia de nação brasileira, cuja tônica residia na exaltação de uma figura idealizada do índio. Destacam-se os poetas Gonçalves Dias (1823-1864) e o romancista José de Alencar (1829-1877).
} 
dados do IBGE (2010), divididos em, pelo menos, três troncos linguísticos. Se a elaboração pejorativa do indígena como selvagem e preguiçoso se constrói como obviamente contraproducente, a noção de uma população ingênua ou de uma nobreza selvagem, de modo similar, por ser uma idealização, também dificulta a percepção dessa população verdadeiramente como sujeitos históricos e contemporâneos, posto que pode não coincidir automaticamente com os indígenas que se encontram nas interações cotidianas, especialmente nos casos daqueles que residem muito proximamente ao contexto urbano.

Dessa forma, o propósito deste trabalho é refletir como a escola estudada representou as comunidades indígenas com base em um olhar desenssencializador, e engrossar o movimento por descolonização do pensamento (LANDER, 2005; PIMENTEL, 2014). Uma das formas de fazêlo seria a promoção, dentro do espaço escolar, de materiais mais adequados, sempre que possível, produzidos pelos próprios indígenas, como forma de disputar e romper com a representação colonial que se faz sobre essa população.

Antes mesmo de adentrar à questão do material didático e das atividades escolares, é mister salientar os significados da palavra índio. A terminologia foi criada para dar conta de uma ordem colonial, seja na sua versão quinhentista, seja na nacionalista (BONFIL BATALLA, 1997). Essa noção suporta tanto uma homogeneização (OLIVEIRA, 2005) quanto uma relação hierárquica, além dos famosos componentes de uma confusão geográfica por parte dos invasores que chegaram à América imaginando ser a Índia, localidade. A imensa variedade interna dessa categoria é suprimida e colocada em inferioridade em relação ao colonizador, que pode ser uma metrópole ou um Estado-nacional, a população europeia ou a brasileira.

A palavra indígena é outro termo também usado e não se equivale completamente a índio. A primeira remete ao nativo de algum lugar, em contraposição a populações estrangeiras. O segundo equivale aos descendentes dos nativos americanos em contraposição ao branco (termo genérico para designar os não índios, do ponto de vista indígena). Há povos indígenas por todo o mundo (aborígenes na Austrália, por exemplo), mas índios são os descendentes que se reconhecem e são reconhecidos por suas comunidades como pertencentes a povos que habitavam o continente americano antes da invasão europeia (VIVEIROS DE CASTRO, 2017). No contexto da América Latina, diferentemente do Brasil, essas populações preferem a denominação "povos originários". Dentro de uma referência mais abrangente, de certa linha da etnologia, emprega-se também a palavra ameríndios (VIVEIROS DE CASTRO, 2002), por exemplo, especialmente na tentativa de marcar uma visão de mundo elaborada por esses povos nativos do continente, conhecida na literatura por perspectivismo.

Uma longa história de luta, de genocídios e de resistências se passou desde o momento em que foram chamados de índios. E quando pensamos nessa categoria, devemos entender como sendo parte de um momento de inflexão, a Constituição de 1988 no Brasil e o panindianismo da década de 1960, que ressignificaram tal termo. Do mesmo 
modo, como a palavra e o autorreconhecimento - tal como negro vem se transformando de um epíteto ofensivo em emblema de luta -, o termo índio, antes evitado pelos próprios, passou a se erigir como emblema identitário de resistência (CARDOSO DE OLIVEIRA, 2000). Índios são os membros das comunidades indígenas que se autorreconhecem e que também são reconhecidos por suas comunidades, as quais mantêm laços histórico-culturais com as sociedades pré-colombianas.

No Brasil, juridicamente, a Fundação Nacional do Índio é o órgão indigenista oficial do estado e está encarregado, dentre outras funções, de chancelar juridicamente tais comunidades ao acesso a direitos específicos $^{9}$. A identificação índio é mais do que o remetimento a uma ascendência, designa um posicionamento político de valorização identitária ressignificado ${ }^{10}$ e um acesso a direitos específicos frente ao estado nacional. É nesse contexto que a Lei $n^{\circ} 11645 / 08$ deve ser pensada. E é isso que faremos neste artigo.

\section{Os índios nos livros didáticos}

Grande parte da informação reproduzida na escola sobre as sociedades indígenas advém da elaboração produzida nos livros didáticos, com seu sentido de verdade científica e oficial. Tal material é mercadoria, substituível e descartável (MUNAKATA 2012), além de objeto cultural e de controle (CHARTIER, 1999), na medida em que produz uma realidade num discurso oficial (APPLE, 2006). Logo, trata-se de um objeto de grande disputa política, pois educar a todos coloca a questão sobre o que se deve aprender. O livro didático é amplamente utilizado como, talvez, a principal fonte de informação para os professores (BITTENCOURT, 2004).

Diante dessa relevância como fonte central de informação dos professores, é interessante construir um panorama sobre as representações das sociedades indígenas em livros didáticos antes da promulgação da Lei $n^{\circ} 11645 / 08$. Segundo as diretrizes curriculares, o conteúdo referente à temática indígena deve ser ministrado em todo currículo, especialmente nas disciplinas Histórias Brasileiras, Educação Artística e Literatura (BRASIL, 2013). Contudo, sabemos que a temática foi tradicionalmente abordada na matéria História. Pela centralidade dos livros didáticos na elaboração sobre as representações acerca das sociedades indígenas, a seguir, faremos uma breve sumarização sobre a forma como as representações sobre a figura dos índios foram abordadas em alguns destes materiais educativos.

A partir de Mariano (2006) e Oliveira (2005), que estudaram como os livros didáticos trataram a temática indígena em um período anterior à lei, é possível afirmar que os manuais escolares do início do século XX

\footnotetext{
${ }^{9}$ Para uma reflexão detalhada sobre o que significa ser indígena, especialmente no Brasil, ver Viveiros de Castro (2006). Para um bom panorama histórico sobre os direitos indígenas, ver Carneiro da Cunha (2012).

${ }^{10}$ Cabe observar que os termos são sempre polissêmicos e contextuais, pois há lideranças indígenas que preferem o termo indígena a índio, ou, ainda, procuram valorizar mais o etnômio (ex. sou guarani, sou atikum, etc.).
} 
também reproduziram a duplicidade idealizada entre nobre e selvagem, especialmente nas obras patrocinadas pelo Instituto Histórico e Geográfico Brasileiro" ', que tinha a missão de fabricar uma historiografia oficial e positiva da nação em construção. Por exemplo, em Lições de história do Brazil (1907), do romancista Joaquim Manoel de Macedo, no capítulo sobre os indígenas, que o autor denomina de gentios, descreveos sob o signo da falta e da carência: simples, incultos e com defeitos e vícios próprios dos selvagens, numa trilogia já bem conhecida, "sem fé, sem lei e sem rei". Inversamente, na obra Porque me ufano de meu paiz, (1900), de Affonso Celso, na qual o poeta, político e tradutor procura tecer as razões da superioridade do Brasil, as considerações sobre os indígenas, que, segundo ele, conformam classicamente o tipo nacional, juntamente com o negro e o branco português, recaem sobre a hospitalidade e nobilidade, em especial referentes à aliança com os portugueses na formação da "nação rica, grandiosa e pacífica".

Mariano (2006), ao refletir sobre as mudanças e as permanências dos indígenas nos livros didáticos, acerca das obras utilizadas no final do século passado, pontua a imagem de índio genérico, especialmente de língua tupi, os habitantes do litoral com suas ocas, pajés, caciques, eventualmente canibais e designados pelo termo "selvagens". Isso em obras publicadas em 1997, como no livro História: das cavernas ao terceiro milênio, que intitula o capítulo dedicado aos indígenas, na primeira edição, por Os hóspedes da América. Na segunda edição, de 2002, o conteúdo foi intitulado Os diferentes povos da América, o que já demonstra um movimento em direção a uma outra abordagem. De todo modo, esse achatamento da realidade produzida em obras escolares informa grande parte do conhecimento não indígena sobre os indígenas. A não percepção sobre o tamanho da diversidade de tais populações, suas tremendas diferenças linguísticas e de modos de vida opera como redutor enganoso da realidade, conduzindo ao questionamento da indianidade desses sujeitos na contemporaneidade.

Outro elemento complicador dessa elaboração escolar foi o tratamento pretérito dado à população indígena, como já bem demonstrou Grupioni (1995). Seja no livro didático, seja no cotidiano das falas de professores e discentes, observamos, na descrição sobre as coisas indígenas, a utilização de verbos no passado, como se essa população não compartilhasse o presente. Parece que, de um lado, contemporaneamente, não há muitos indígenas ou há cada vez menos; de outro, em retrospectiva, o discurso sobre o território é de um avançar sobre o vazio, ou seja, um duplo apagamento no passado e no presente. Dessa forma, as palavras "os índios viviam, moravam, eram, comiam" tornam-se o grande balizador no que concerne à descrição das condutas indígenas, compondo um imaginário difícil de descontruir. Esse é um dos efeitos da abordagem dada a essa questão nas escolas, ainda que não corresponda a realidade, já que de acordo com o censo do IBGE (2010),

\footnotetext{
${ }^{11}$ Como mostra Schwarcz (1989), por meio de uma prática laudatória, festiva e de criação de símbolos nacionais, o Instituto atuava num processo inventivo de uma história nacional e patriótica, nomeando heróis, fatos históricos relevantes e promovendo uma imagem específica com relação ao indígena.
} 
os indígenas representam 896.917 pessoas, numa curva demográfica ascendente.

De 1991-2000, a população indígena cresceu a uma taxa de 10,8\% ao ano. Obviamente esse número não reflete um efeito demográfico per se, mas uma política de reconhecimento pós-democratização. De 2000 a 2010 essa taxa de crescimento se estabilizou perto da média nacional, 1,2 (IBGE, 2012). Ou seja, essa população não está desaparecendo, ainda que algumas etnias contem com poucos representantes: sete povos têm entre 7 e 45 indivíduos (INSTITUTO SOCIOAMBIENTAL, 2011) ${ }^{12}$. Esse aumento de população indígena, até mesmo, parece ser uma tendência global. No mundo, atualmente, temos mais de cinco mil povos que somam 370 milhões de pessoas, em crescimento demográfico desde meados da década de 1980 (IWGIA, 2015).

Ainda que essa breve excursão tenha sido realizada sobre o material didático produzido antes de Lei $n^{0} 11.645 / 08$, sabemos que há uma diferença constitutiva entre o material oficial e sua concretização prática. Pretendemos, assim, com este artigo pensar microssociologicamente (GEERTZ, 2008 [1973]) como a imagem dessas populações foi construída no interior de um contexto específico e demonstrar os desafios da implementação da lei e da superação das formas tradicionais de abordagem dessa questão.

\section{Os índios na prática escolar}

A pesquisa e o texto foram realizados numa parceria entre orientador e orientanda. $O$ contexto refere-se a uma escola pública do município de Jequié, no sudoeste da Bahia, que atende alunos do primeiro ao quinto ano do Ensino Fundamental. A escolha da instituição foi facilitada por relações prévias de estágio durante a graduação da autora. A escola, fundada na década de 1970, está situada num bairro periférico, oferece ensino do primeiro ao quinto ano e atende, nos dois turnos, cerca de 450 estudantes de bairros contíguos.

A ideia inicial era acompanhar os preparativos escolares para o 19 de abril, desde o início do ano letivo. Foram realizadas várias visitas à escola, com acesso ao material didático disponibilizado aos professores para o trabalho da temática, conversas com a gestora, a coordenadora pedagógica e algumas docentes, além do acompanhamento consentido de uma docente do primeiro ano a partir do momento em que o tema fosse abordado. O material didático selecionado pela direção e 0 acompanhamento da atividade foram as fontes principais dos dados, em um estudo que combinou instrumentos da pesquisa etnográfica, como observação participante, além das leituras dos documentos da escola.

Em conversa com a coordenadora pedagógica da instituição, a profissional afirmou que a escola não realizava um projeto específico para

\footnotetext{
$12 \mathrm{O}$ Instituto Socioambiental é um grande compilador de informações confiáveis sobre as sociedades indígenas. Dentre as principais publicações vinculadas ao Instituto se destacam Guarani continental, Mineração nas terras indígenas na Amazônia brasileira, Povos indígenas no Brasil e Enciclopédia dos povos indígenas no Brasil.
} 
o Dia do Índio. Segundo ela, a instituição trata de maneira sucinta o assunto e outras datas como o Dia do Descobrimento do Brasil. Porém disse que não deixa tais dias passarem "em branco". Solicitamos à coordenadora da escola a permissão para acompanhar as reuniões de planejamento dos materiais e as estratégias de abordagem da temática. O consentimento foi obtido, mas nas visitas para acompanhar o planejamento, não houve nenhuma reunião, nem previsão de encontros para uma discussão específica, indicativo da indiferença ou da forma automática, sem a detida reflexão, de que o tema costuma ser abordado na escola.

Ao analisar o Projeto Político Pedagógico da instituição, surpreendeu-nos a presença da temática em sua forma contemporânea e adequada à lei. A direção permitiu que consultássemos o documento, que estava em fase de elaboração. Não nos foi permitido fazer uma cópia. Portanto, as citações presentes neste artigo registram a versão provisória do documento a que tive acesso. O projeto no item Visão da Educação aborda que: "a escola deve cultivar, em seus currículos, a aprendizagem básica para a convivência social e para a construção de uma sociedade mais justa e igualitária, sem exploração e dominação". No item Visão de Sociedade, afirma que "quando se pensa a formação docente, deve-se pensar na relação entre a formação e a qualidade do ensino na busca de alternativas pedagógicas para entender a favor de quem o currículo trabalha e como fazê-lo trabalhar a favor dos grupos e classes oprimidos.".

Para o tratamento da temática indígena, especialmente em 19 de abril, o projeto sugeria os seguintes assuntos: o índio ontem e hoje; a utilização de músicas indígenas; a leitura e produção de textos com o tema "Índios: primeiros donos dessa terra!"; a valorização da cultura indígena; a realização de colagens/pinturas; aulas expositivas com a participação dos discentes; a confecção de painel com cada sala se responsabilizando por um conteúdo (costumes, vestes, alimentação, etc.); e a discussão sobre a inclusão do índio. Ou seja, ainda que a forma como cada uma dessas atividades é conduzida seja de fundamental importância para proporcionar ou não um entendimento mais adequado da realidade indígena, o fato é que há elementos no projeto que indicam a possibilidade de um tratamento a contento, como a comparação entre a realidade pretérita e atual ou, ainda, a discussão sobre inclusão. Infelizmente, como veremos, mesmo diante de proposições pertinentes, a escolha das atividades reforça estereótipos. Percebemos que a instituição tem uma proposta em seu documento diversificada, que poderia ser utilizada como base para pensar metodologias a fim de tratar mais criticamente a temática em questão. No entanto, na escolha das tarefas, a discussão predominante foi o tratamento das populações indígenas enquanto essências e pertencentes ao passado colonial.

O material disponibilizado para os professores e guardado numa caixa com outras atividades para datas comemorativas continha três exercícios para o Dia do Índio. Ao lado do índio, as demais datas contempladas foram o folclore (22 de agosto), o livro infantil ( 18 de abril), a árvore (21 de setembro) e o descobrimento (22 de abril). A atividade 1 
continha um desenho que pretendia representar um índio e um europeu conversando. O diálogo dava-se da seguinte maneira: o europeu perguntando ao índio: "O Brasil foi descoberto ou invadido?". O índio respondia: "Quem descobriu o Brasil? Dizem que foi Cabral. Como? Se quando ele saiu, chegou e encontrou tanta gente!". Na mesma atividade há um pequeno texto sobre "um país chamado Portugal", que necessitava de novos produtos para aumentar seu comércio, o que acarretou suas aventuras ao mar e que, personalizado sob a figura de Pedro Alvares Cabral, chegou a uma terra diferente, habitada por pessoas que foram denominadas índios. O texto concluiu que, a partir dessa data, os portugueses exploraram as riquezas do Brasil e mataram a maioria dos índios. Essa escravidão durou trezentos anos.

É interessante notar que, embora a atividade marque um processo de violência, ela o faça de forma a um remetimento remoto, visto que os culpados pelo massacre e escravização são os outros, não um outro radical, mas um outro ancestral, os portugueses, com sua sede por lucros, os grandes exploradores das riquezas naturais e da população brasileira, num tom de discurso nacionalista antilusitano, marcando, inclusive, uma diferença com os verdadeiros donos da terra no presente, os brasileiros. Soma-se a isso a noção de que a população foi inteiramente exterminada, sem resistência, desconsiderando toda uma política de amizades e inimizades do passado, assim como as mais de oitocentas mil pessoas do presente. Nesse sentido, em alguns casos, ao se descrever uma violência, apaga-se a história do grupo que a sofreu, pois apresenta-o apenas como passivo no processo histórico.

A atividade 2 , um pouco mais complexa e informativa, apresentava um texto mais longo e com várias informações sobre o modo de vida dos índios. O material afirma que eles viviam aqui antes da chegada dos portugueses e "foram" os primeiros habitantes do Brasil. Todo o texto está escrito no passado: os índios se "enfeitavam" com penas, "moravam" em ocas, "realizavam" festas, "alimentavam-se" da caça, da pesca e de frutas. Mesmo quando cita a organização social da "tribo", fala-se apenas no passado, que "as tarefas eram divididas entre homens e mulheres", "em cada tribo havia um chefe guerreiro chamado cacique", "os índios acreditavam na existência de muitos deuses", dentre eles Tupã, a lua Jaci e o sol Guaraci, "o chefe religioso, chamado pajé, era não só guia espiritual, como também aquele que cuidava dos doentes", "suas festas eram animadas, cantavam, dançavam e tocavam instrumentos", "fabricavam cestos, objetos de cerâmica e madeira, colares".

O texto, ao final, ressalta que existiam grandes nações indígenas, especialmente os tupis, os quais viviam no litoral e, ainda hoje, há tribos vivendo em parques criados pelo governo, enquanto alguns vivem em cidades ou nas proximidades. Cita também que o governo criou um órgão, a Fundação Nacional do Índio (Funai), para protegê-los e garantir seus direitos. Ou seja, é uma atividade com grande ênfase no passado, com uma predominância de informações sobre os índios tupi que viviam na costa marítima e com as informações sobre o presente ocupando papel secundário. 
A motivação de um tratamento desse tipo deriva da utilização de conceitos híbridos, antropológicos e do senso comum, como "aculturação" e "contribuições culturais", além de ideias evolucionistas e colonizadoras $^{13}$. Há todo um repertório misto de senso comum e de teorias antropológicas defasadas (entre antropólogos) que pensam a cultura como um conjunto de "traços culturais originais", que podem ser perdidos por diversas populações, num processo de aculturação ou perda cultural. Esse processo refere-se especialmente às sociedades não ocidentais, pois na autorrepresentação das ocidentais sua própria mudança cultural é pensada como evolução. Esse modo de conceber a cultura já foi amplamente desconstruído, tanto pela noção de fricção interétnica (CARDOSO DE OLIVEIRA, 1964), quanto por teorias que pensam modos nativos de historicidade (SAHLINS, 1991). Toda sociedade vive a história de modos específicos num contínuo processo de ressignificação dos acontecimentos presentes.

É extremamente comum a noção de que os indígenas atuais são aculturados porque não vivem mais como seus antepassados, o que também detona a dificuldade de reconhecimento deles na contemporaneidade. Bebendo de uma vertente que pensa a cultura de uma forma reificada, num jogo de perdas e ganhos "originais", antropólogos como Darcy Ribeiro (RIBEIRO, 1977), e sua preocupação acerca do processo de aculturação e integração à sociedade nacional, reforçaram uma ideia específica sobre o processo de mudança cultural no que se refere às sociedades indígenas. Uma concepção estática de cultura $^{14}$, especialmente no que tange ao Outro, é a tônica dessa miragem: aculturados e em processo de desaparecimento, tal imagem alimenta o senso comum difundido na escola sobre os indígenas. A diferença entre o índio do livro e o índio observado colabora no questionamento da indianidade deste, jamais num questionamento daquele.

$\mathrm{Na}$ atividade 2, não há informações sobre os índios contemporâneos, e o exercício de completar frases - logo abaixo ao texto proposto - não favorece a reflexão sobre questões pertinentes à situação indígena, como os processos de catequização e violência que sofreram e as lutas realizadas até hoje, a exemplo da demarcação de suas terras. Nas representações escolares também há uma essencialização tupi, o que nem de perto reflete a diversidade pretérita e contemporânea.

A essencialização de um tupi dos livros e práticas escolares - que, diga-se de passagem, é reproduzida desde o século XVI, em outras bases, nos relatos de jesuítas e cronistas ${ }^{15}$-, a elaboração do indígena como um ser pretérito a caminho da extinção e uma descrição operada pelo viés da falta - sem comércio, sem dinheiro, sem escrita, numa economia de subsistência, sem religião, sem estado - operam a construção da imagem

\footnotetext{
${ }^{13}$ Para uma coletânea de textos dos antropólogos evolucionistas e uma reflexão dessas obras no presente, ver Castro (2005) e, na sala de aula, Pimentel (2015).

${ }^{14}$ Para uma noção mais contemporânea de cultura, ver Wagner (2010 [1975]); para um panorama sobre os desdobramentos de uma concepção estática de cultura sobre as sociedades indígenas, ver Cohn (2001).

${ }^{15}$ Carneiro da Cunha (2012, p. 48) fala de um etnocentrismo tupi nesses relatos seiscentistas, que reproduz a dicotomia índios amigos versus índios inimigos e bárbaros, contra os quais se pode uma guerra justa. Esse aspecto também será observado em autores que se debruçam sobre os materiais escolares, como Mariano (2006).
} 
das populações indígenas ainda na contemporaneidade. Uma descrição pelo negativo, ilustrando especialmente o que a eles falta(va) se comparados à sociedade nacional, sem um questionamento antietnocêntrico, descolonizador, que vise construir uma ideia pelas produções relevantes indígenas tomando como referência o ponto de vista destes próprios atores sociais. Sem uma noção da diversidade, é impossível o reconhecimento e a valorização como se propõe o Projeto Político Pedagógico da escola.

A atividade 3 , a mais simples das três, tinha uma proposta que não continha texto escrito, apenas um desenho e um enunciado: "As crianças indígenas gostam de tomar banho no rio". Era a pintura de um desenho que consistia em três indiozinhos tomando banho em um rio, e o preenchimento de uma cruzadinha com figuras que representavam uma criança indígena idealizada, carregando um arco correspondendo ao campo índio, uma habitação "tipicamente" indígena referida por maloca, um arco, uma borduna e uma flecha.

Das três atividades, essa era a menos reflexiva, ao se considerar a forma proposta no material. A associação índio-natureza e os objetos "tipicamente" indígenas reforçam a idealização edênica de um índio préConquista, o que trabalha na facilitação do questionamento da indianidade contemporânea dos que não vivem na floresta. A comparação que se pode fazer entre as atividades e a realidade dos povos indígenas traz indagações sobre esses sujeitos, mas não sobre a sua produção oficial e simulada nos materiais escolares. O bom selvagem tem seu lugar garantido na escola.

A reprodução estereotípica de um índio idealizado corresponde muito proximamente com a forma como a sociedade nacional constrói e dissemina seus preconceitos. Florestan Fernandes já dizia que os brasileiros têm "preconceito de ter preconceito" (FERNANDES, 1972, p. 42), ou seja, é no olhar sobre a aparente não violência transformada em regras de etiqueta que se observa, por exemplo, o racismo no Brasil. Mais do que elaborar um processo de discriminação ostensivo, são criadas formas de se suavizar a relação de desigualdade e de preconceito, do qual o termo "moreno" (MUNANGA, 2004; NOGUEIRA, 2006) é o exemplo clássico de como se foge de abordagens sobre o racismo, sem mencionar uma ideia de "negritude" como um aspecto supostamente aviltante.

No caso da escola em questão, o material reproduz a idealização de uma população, seu modo de ser, sem considerar os aspectos presentes, embora não construa uma imagem ostensivamente pejorativa - por exemplo, do índio preguiçoso - ao idealizar um indígena préConquista, sem remetimento ao presente, a escola foge do problema da discriminação atual, construindo um estereótipo que colabora no não reconhecimento e no preconceito com relação aos indígenas do presente. Cardoso de Oliveira (2003, p. 127-128) relata, até mesmo, que essa representação tem consequências robustas no contato próximo entre populações indígenas e a nacional. Em 1957, ao sugerir que uma professora de uma escola próxima a uma terra indígena solicitasse aos discentes (de sete a onze anos) que fizessem alguma composição sobre os hábitos e costumes indígenas, não foi de surpreender que eles 
apresentaram o índio abstrato dos livros escolares, e não os Terena, que frequentavam a escola e os quais eram tidos por bugres, decadentes, misturados e alcoólatras. Os próprios três terenas da classe construíram, com menos entusiasmo, uma representação idealizada de índio. Ou seja, diante de um contexto muito adverso de disputa por terras, a duplicidade representacional bugre - índio idealizado operou com tal força, que silenciou os próprios terenas.

Em 16 de abril, poucos dias antes da realização da atividade comemorativa, a coordenação da escola apresentou essas três possíveis atividades, as quais deveriam ser escolhidas pelos professores. A coordenação enfatizou que abordaria o tema indígena, mas de forma sucinta. Interessante pensar que num pequeno intervalo de dias, a instituição abordou Descobrimento e não invasão e, ainda, construiu uma imagem estereotipada da população indígena.

Além disso, celebrou o livro infantil com base na obra de Monteiro Lobato, com seus personagens vilipendiosos em relação à população negra e cabocla/indígena. Jeca Tatu, famoso personagem criado pelo autor para ilustrar o caboclo substitui a imagem idealizada de um índio pré-Conquista por sua completa antítese, o preguiçoso e cachaceiro, o "funesto parasita da terra", que "não se liga a terra como o campônio europeu", o qual toca-se da terra como um cachorro importuno (LOBATO, 1994 [1918]). Fazemos uma ressalva de que o importante aqui não é uma crítica literária ou das ideias defendidas pelo autor em sua vasta obra, mas sim o uso que as escolas fazem de diversas temáticas, passando pelo Dia do Livro Infantil e, na celebração de Monteiro Lobato, reforçando a promoção de uma visão muito específica sobre o país, com estereótipos negativos oficializados nessas práticas sobre grande parte da população brasileira, se somarmos indígenas e negros. ${ }^{16}$

Dessa forma, sabemos que a instituição de datas comemorativas se relaciona a um processo de invenção da tradição, criação de símbolos e de uma historiografia oficial com a exaltação de uma elite (HOBSBAWN; RANGER, 1997 [1983]), uma verdadeira batalha pela memória, vide "heróis do Descobrimento", com visibilidade portuguesa e invisibilidade indígena; a proclamação da República e uma nova elite política; o feriado da Revolução Constitucionalista de 1932, comemorado no estado de São Paulo; ou a Semana da Revolução Democrática de 1964 em alguns círculos militares, em comemoração ao Golpe Civil-Militar. Ainda que esse processo de invenção possa ser também utilizado por grupos subalternizados, como o Dia da Consciência Negra, no caso específico do Dia do Índio, percebe-se uma ressignificação de um dia de luta política para uma data de reforço de estereótipos negativos com relação a essa população.

A data é comemorada em todo o continente americano em referência ao Primeiro Congresso Indigenista Interamericano, realizado em 1940, no México. No Brasil, a celebração foi instituída em 1943 (BRASIL, 5540/1943). A recomendação 59 do Primeiro Congresso

\footnotetext{
${ }^{16}$ Para uma leitura sobre a obra de Monteiro Lobato, a construção da nação e o caráter brasileiro, ver Moraes, 1997.
} 
estabelecia que o dia deveria ser utilizado para o estudo do problema do índio atual nas instituições de ensino. Contudo, sua finalidade é ressignificada no cotidiano escolar, promovendo um estereótipo colonialista e racista.

$\mathrm{Na}$ escola pesquisada, as atividades do Dia do Índio ocorreram no dia 22 de abril, pois não houve tempo hábil de abordar o assunto durante a "Semana do Descobrimento", com seu feriado. Na data acertada, a docente que havia escolhido a realização da atividade 3 e a confecção de um colar, iniciou a aula com uma oração e uma canção de abertura das tarefas. Em seguida, questionou os estudantes sobre o mês de abril, que era "rico em comemorações", se eles saberiam sobre isso. Falou brevemente sobre Tiradentes, "um homem que lutou pelo Brasil" e sobre o dia do livro infantil e aniversário do escritor Monteiro Lobato. Na sala, havia um cartaz sobre o Dia do Descobrimento e outro sobre o Dia do Índio, com um índio e um português, este estendendo a mão para aquele, um remetimento óbvio à ideologia da formação nacional como um grande encontro entre populações.

A professora começou a falar sobre o Dia do Índio, explicando aos discentes que os índios eram pessoas que moravam no Brasil antes dos portugueses e que foram chamados assim porque estes achavam que tinham chegado à Índia, pois os desbravadores estavam viajando em busca de especiarias. Para ela, "antes" os índios se alimentavam de peixes, frutas e animais, e se enfeitavam, chamando a atenção para as diferenças entre a forma de se vestir entre portugueses e índios, afirmando que tal encontro representou um choque de culturas. A professora também citou que os portugueses achavam sua cultura superior.

Ela falou um pouco sobre a divisão do trabalho indígena, pois homens e mulheres têm tarefas distintas. Citou também que os índios utilizavam uma pintura para cada ocasião e que adoravam muitos deuses, como o sol e a lua. Salientou que nós adoramos um só Deus, o que segundo ela é muito melhor. A docente afirmou que os índios foram massacrados, e que hoje não existem etnias diferentes por causa da miscigenação. Finalizou que ainda existem índios vivendo em tribos.

A atividade escolhida pela professora foi a terceira, uma cruzadinha com objetos atribuídos à cultura indígena. Ela desenhou a cruzadinha no quadro e perguntava aos discentes os nomes dos objetos. As figuras eram pequenas e de difícil compreensão, e um dos objetos foi identificado como uma corneta, mas provavelmente se tratava de uma borduna. Depois de preenchida, os discentes pintaram o desenho, na folha, de dois índios tomando banho em um rio. Em seguida, a tarefa foi colada no caderno, houve o intervalo para o lanche. Na volta sentaram em círculo e receberam os canudinhos para confeccionarem os colares. Não houve nenhum comentário ou explicação da professora durante ou após essa atividade, o que comprometeu o significado da prática. A confecção encerrou a aula sobre a temática indígena. 


\section{Considerações finais ou o que se pode evitar no tratamento da questão indígena na escola}

Embora este artigo tenha se debruçado sobre a atividade de uma escola específica e os detalhes não possam ser generalizados, a experiência pessoal e a bibliografia citada sobre o tema nos informam que há um modus operandi sobre a questão indígena que é reproduzido em muitas escolas brasileiras. Essa forma inclui um processo de invisibilização, que só é quebrado durante alguns dias do mês de abril, em ampla medida, de modo estereotipado e racista.

Pimentel (2012) aponta que um grande obstáculo a abordagem adequada da temática indígena relaciona-se menos àquilo que os brasileiros não sabem sobre essas populações e mais sobre aquilo que se pensa conhecer. "Qual o índio que mora na sua cabeça?" é uma pergunta atual, urgente e sintonizada com a Lei $n^{\circ} 11645 / 08$. É um questionamento genuíno que deve ser feito por todos, especialmente pelos educadores. A complexidade e a variedade das sociedades em questão sugerem que não utilizemos a ideia de um índio genérico. É muito importante trabalhar com comunidades específicas, na tentativa de despertar nos discentes a noção de diversidade, aproximando-se ao índio contemporâneo e desconstruindo o estereótipo genérico amplamente reproduzido na escola, talvez refletindo sobre populações indígenas do convívio cotidiano.

Como lados de uma mesma moeda, outra representação a ser atacada é a que se relaciona a uma noção de congelamento das culturas indígenas no passado, juntamente com a obsessão por abordá-las apenas no Brasil Colônia, como se essas sociedades não compartilhassem a contemporaneidade. É imprescindível se debruçar sobre as questões indígenas atuais: etnias específicas, a questão da terra e do meio ambiente, o direito de manter sua própria língua, os problemas que enfrentam em termos de educação e saúde, seus modos de vida atuais, suas produções literárias e audiovisuais, mitos e ritos vivos e pulsantes, suas formas de resistência, seu direito de existir conforme sua cultura.

Não pretendemos com este trabalho indicar formas de abordagem. A ideia foi problematizar os tratamentos tradicionais e sugerir especialmente o que não se deve fazer quando a temática está em questão. ${ }^{17}$ Se há um problema de abordagem na escola isto significa que ela decorre em grande medida da formação universitária, que também não coloca a questão indígena em evidência no período de formação de professores. Talvez essa realidade também se transforme à medida que a população indígena acesse cada vez mais a universidade, o que vem ocorrendo especialmente a partir de 2012, por meio da Lei de Cotas (Lei

\footnotetext{
${ }^{17}$ Curiosamente ao finalizarmos a revisão do artigo, o canal TV Futura lançou uma série intitulada Índio Presente, dirigida por Bruno Vilela e Sérgio Lobato. Em 13 episódios, a série tem o objetivo de desfazer equívocos comuns sobre as sociedades indígenas: que estão acabando; perdendo a cultura; qualquer um pode ser índio; a Igreja os conquistou; todos falam tupi; eles são preguiçosos; são incapazes e precisam ser tutelados; não respondem pelos seus atos; não vivem em cidades; possuem muita terra; são atrasados; atrapalham o desenvolvimento; e pertencem ao passado.
} 
12.711/2012). A presença e a mobilização dessa comunidade na universidade podem alterar os estereótipos enraizados.

$\mathrm{Na}$ descolonização do pensamento, do currículo e da prática escolar é necessário aproximar teoria de prática, e recuperar um papel ativo do professor frente aos materiais escolares, não apenas os reproduzindo, mas principalmente problematizando-os e direcionando a reflexão para aspectos contemporâneos e do dia a dia dos discentes (KHAN; MORGADO, 2013). Cada professor deve, criativa e autonomamente, realizar sua própria pesquisa com base em fontes confiáveis e construir sua metodologia particular. A temática é complexa, são muitas as sociedades indígenas e cada uma vive uma realidade específica. A Lei $n^{\circ} 11645 / 08$ não é somente uma normativa para a não invisibilização dessas populações, trata-se de uma ação afirmativa que compõe uma política de resistência cultural e de combate ao etnocídio perpetrado pelo Estado nacional num processo de Conquista que não cessou. A escola, que tanto contribui para a formação de um estereótipo sobre os índios, agora tem a oportunidade de ser uma frente de resistência e de combate ao preconceito. 


\section{Referências bibliográficas}

APPLE, M. W. Ideologia e currículo. 3. ed. São Paulo: Brasiliense, 2006.

BERGAMASCHI, M. A.; GOMES, L. B. A temática indígena na escola: ensaios de educação intercultural. Currículo sem Fronteiras, v.12, n.1, pp. 53-69, 2012. Disponível em: < http://www.curriculosemfronteiras.org/vol12iss1articles/bergamaschi-gomes.pdf $>$ Acesso em: 10 ago. 2018.

BESSA FREIRE, J. R. Cinco ideias equivocadas sobre o índio. Cenesch Revista do Centro de Estudos do Comportamento Humano, Manaus, v. 1, p. 17-33, 2000.

BETTENCOURT, L. Cartas brasileiras: visão e revisão dos índios. In: GRUPIONI, Luís Donisete Benzi. (Org.). Índios no Brasil. São Paulo: Global, 1998. p. 39-46.

BITTENCOURT, C. M. F. Ensino de história: fundamentos e métodos. São Paulo: Cortez, 2004.

BONFIL BATALLA, G. El concepto de Indio en América Latina: una categoría de la situación colonial, Boletín Bibliográfico de Antropología Americana, 48, 1997, pp. 17 32 .

BRASIL. Decreto-lei de 2 de junho de 1943. Considera Dia do Índio a data de 19 de abril. Diário Oficial da União, Brasília, DF, 4 jun. 1943, Seção 1, p. 8704.

Lei de Diretrizes e Bases da Educação Nacional. Lei número 9394, 20 de dezembro de 1996.

Plano Nacional de Implementação das diretrizes curriculares nacionais para educação das relações etnicorraciais e para o ensino de história e cultura afro-brasileira e africana. 2009.

Lei $\mathrm{n}^{\mathrm{o}} 11.645$, de 10 de março de 2008. Altera a Lei no 9.394, de 20 de dezembro de 1996, que estabelece as diretrizes e bases da educação nacional e a Lei $\mathrm{n}^{\circ}$ 10.639, de 09 de janeiro de 2003, para incluir no currículo oficial da Rede de Ensino a obrigatoriedade da temática "História e Cultura Afro-Brasileira e Indígena", e dá outras providências. Diário Oficial [da] República Federativa do Brasil, Brasília, DF, 10 mar. 2008.

. Lei 12.711 em 29 de agosto de 2012. Dispõe sobre o ingresso nas universidades federais e nas instituições federais de ensino técnico de nível médio e dá outras providências. Diário Oficial da União, Brasília, DF, Seção 1, p. 1, 30 ago. 2012a.

Plano nacional de implementação das diretrizes curriculares nacionais para educação das relações étnico-raciais e para o ensino de história e cultura afrobrasileira e africana. / Ministério da Educação, Secretaria de Educação Continuada, Alfabetização, Diversidade e Inclusão. Brasília: MEC, SECADI, 2013.

CASTRO, C. Evolucionismo Cultural: textos de Morgan, Tylor e Frazer. Rio de Janeiro: Jorge Zahar Editor, 2005. 
Espaço Ameríndio

CHARTIER, R. A ordem dos livros: leitores, autores e bibliotecas na Europa entre os séculos XIV e XVIII. Tradução Mary del Priore. Brasília: UnB, 1999.

CARDOSO DE OLIVEIRA, R. O índio e o mundo dos brancos. São Paulo, Difusão Européia do Livro, 1964.

. O índio da consciência nacional. In: A sociologia do Brasil indígena. São Paulo: Tempo Brasileiro, 1971.

Os (des)caminhos da identidade. Rev. bras. Ci. Soc., São Paulo, v. 15, n. 42, p. 7-21, Feb. 2000.

. Identidade étnica, identificação e manipulação. Sociedade e Cultura, v. 6, n. 2, jul./dez. 2003, p. 117-13.

CASANOVA, P. Colonialismo Interno: uma redefinição. In: BORON, Atílio et al. (Comp.). La teoría marxista hoy: problemas y perspectivas. Buenos Aires: CLACSO, 2006.

COHN, C. Culturas em transformação: os índios e a civilização. São Paulo Perspec., São Paulo, v. 15, n. 2, p. 36-42, Apr. 2001.

CUNHA, M. C. Política indigenista no século XIX. In: CUNHA, Manuela Carneiro da. (org). História dos índios no Brasil. São Paulo: Companhia das Letras, Secretaria Municipal de Cultura de São Paulo, 1998.

Índios no Brasil: história, direitos e cidadania. São Paulo: Claro Enigma, 2012.

FERNANDES, F. O negro no mundo dos brancos. São Paulo: Difel, 1972.

FRIED, M. The notion of tribe. Menlo Park, CA: Cummings Publishing Company, 1975.

GEERTZ, C. A interpretação das culturas. Rio de Janeiro: LTC, 2008 [1973].

GRUPIONI, L. D. B. Livros didáticos e fontes de informações sobre as sociedades indígenas no Brasil. In: A temática indígena na escola: novos subsídios para professores de $1^{\circ}$ e $2^{\circ}$ graus. (Orgs.) Aracy Lopes da Silva e Luís Donizete Benzi Grupioni. Brasília: MEC/MA-RI/UNESCO, 1995.

HOBSBAWN, E.; RANGER T. A invenção das tradições. São Paulo: Paz e Terra., 1997 [1983].

IBGE. Censo demográfico de 2010. Fundação Instituto Brasileiro de Geografia e Estatística, dados referentes as populações indígenas, fornecidos em meio eletrônico, 2010.Disponível em https://censo2010.ibge.gov.br/. Acesso em 10 ago. 2018.

Os indígenas no Censo Demográfico 2010: primeiras considerações com base no quesito cor raça. Rio de Janeiro: Instituto Brasileiro de Geografia e Estatística, 2012.

IWGIA. The Indigenous World. Cæcilie Mikkelsen (org.). Dinamarca, Copenhague: 2015. 
Espaço Ameríndio

KHAN, S.; MORGADO, J. C. Caminhos desobedientes: pensar criticamente o contexto português de conhecimento. Configurações. Disponível em: http://configuracoes.revues.org/2014. Acesso em: 10 ago. 2014.

LANDER, E. Ciências Sociais: saberes locais e eurocêntricos. In: (org.) A colonialidade do saber: eurocentrismo e ciências sociais. Perspectivas Latinoamericanas. Edgardo Lander (org). Colección Sur Sur, CLACSO: Ciudad Autônoma de Buenos Aires, Argentina, 2005.

LOBATO, M. Urupês. São Paulo: Brasiliense, 1994 [1918].

MARIANO, N. R. C. A representação sobre os índios nos livros de história do Brasil. Dissertação apresentada ao curso de Mestrado do Programa de Pós-graduação em Educação Popular, Comunicação e Cultura, do Centro de Educação, da Universidade Federal da Paraíba, como requisito à obtenção do título de Mestre. João Pessoa, 2006.

MUNANGA, K. Rediscutindo a mestiçagem no Brasil. Identidade nacional versus identidade negra. 2. ed. Belo Horizonte: Editora Autêntica, 2004.

MOÍSES, B P. Índios livres e índios escravos: os princípios da legislação indigenista no período colonial (séculos XVI a XVIII). In: CUNHA, Manuela Carneiro da. (org). História dos índios no Brasil. São Paulo: Companhia das Letras, Secretaria Municipal de Cultura de São Paulo, 1998.

MORAES, P. R. B. de. 1997. O jeca e a cozinheira: raça e racismo em Monteiro Lobato. Revista de Sociologia e Política, Curitiba, n. 8, p. 99-112, jun.

MOTA, M. B.; BRAIK, P. R. História: das cavernas ao terceiro milênio. São Paulo: Moderna, 1997.

MUNAKATA, K. História que os livros didáticos contam, depois que acabou a ditadura no Brasil. In: FREITAS, Marcos Cezar. (Org.) Historiografia brasileira em perspectiva. São Paulo: Contexto, 1998. p. 271-296.

NOGUEIRA, O. Preconceito racial de marca e preconceito racial de origem. Tempo Social, Revista de Sociologia da USP, v. 19. n.1. São Paulo, 2006.

OLIVEIRA, T. S. Olhares que fazem a "diferença": o índio em livros didáticos e outros artefatos culturais. In: Educação como exercício de diversidade. Brasília: UNESCO/ MEC/ANPED, 2005.

PIMENTEL, Á. A Atitude etnográfica na sala de aula. Realis, v. 4, n. 2, jul-dez, 2014.

Ressonâncias do evolucionismo cultural na sala de aula. Revista Lugares de Educação, v. 5, p. 56-72, 2015.

PIMENTEL, S K. O índio que mora na nossa cabeça. São Paulo, Prumo, 2012.

RIBEIRO, D. Os índios e a civilização: a integração das populações indígenas no Brasil moderno. Petrópolis, Vozes, 1977.

SAHLINS, M. Ilhas de história. Rio de Janeiro, Zahar, 1991. 
Espaço Ameríndio

SCHWARCZ, L. K. M. Os guardiões da nossa história oficial. São Paulo: IDESP, 1989.

VIVEIROS DE CASTRO, E. A inconstância da alma selvagem. São Paulo: Cosac Naify, 2002.

No Brasil todo mundo é índio, exceto quem não é. In: RICARDO, Beto; RICARDO, Fany (Org.). Povos indígenas no Brasil: 2001-2005. São Paulo: Instituto Socioambiental, 2006. p. 41-49. fev. 2017.

. Os Involuntários da Pátria. Aracê. Direitos humanos em Revista. Ano 4, n.5.,

WAGNER, R. A invenção da cultura. Rio de Janeiro: CosacNaify, 2010.

ZAMBONI, E.; BERGAMASCHI, M. A. Povos Indígenas e Ensino de História: memória, movimento e educação. 17. COLE, 2009.

Recebido em: 14/09/2018 * Aprovado em: 07/11/2019* Publicado em: 30/12/2019 